\title{
Quantifying the surface covering, binding and bonding effects of biological soil crusts on soil detachment by overland flow
}

\author{
Fa Liu, ${ }^{1,2}$ Guang-Hui Zhang, ${ }^{2,3 *}$ (iD Fubao Sun, ${ }^{1}$ Hao Wang ${ }^{2,3}$ and Long Sun ${ }^{4}$ \\ ${ }^{1}$ Institute of Geographic Sciences and Natural Resources Research, Chinese Academy of Sciences, Beijing 100101, China \\ ${ }^{2}$ Faculty of Geographic Science, Beijing Normal University, Beijing 100875, China \\ ${ }^{3}$ State Key Laboratory of Earth Surface Processes and Resource Ecology, Beijing Normal University, Beijing 100875, China \\ ${ }^{4}$ State Key Laboratory of Urban and Regional Ecology, Research Center for Eco-Environmental Sciences, Chinese Academy of \\ Sciences, Beijing 100085, China
}

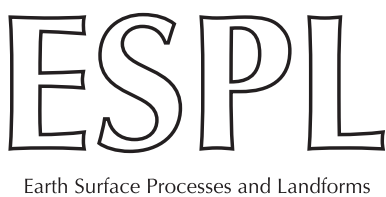

ABSTRACT: Biological soil crusts (BSCs) have impacts on soil detachment process through surface covering, and binding and bonding (B\&B) mechanisms, which might vary with successional stages of BSCs. This study was conducted to quantify the effects of surface covering, binding and bonding of BSCs on soil detachment capacity by overland flow in a $4 \mathrm{~m}$ long hydraulic flume with fixed bed. Two dominant BSC types, developed well in the Loess Plateau (the early successional cyanobacteria and the later successional moss), were tested using natural undisturbed soil samples collected from the abandoned farmlands. Two treatments of undisturbed crusts and one treatment of removing the above-ground tissue of BSCs were designed for each BSC type. For comparison, bare loess soil was used as the baseline. The collected soil samples were subjected to flow scouring under six different shear stresses, ranging from 6.7 to $21.2 \mathrm{~Pa}$. The results showed that soil detachment capacity $\left(D_{c}\right)$ and rill erodibility $\left(K_{r}\right)$ decrease with BSC succession, and the presence of BSCs obviously increased the critical shear stress, especially for the later successional moss crust. For the early successional cyanobacteria crust, $D_{C}$ was reduced by $69.2 \%$ compared to the bare loess soil, where $37.7 \%$ and $31.5 \%$ are attributed to the surface covering and $\mathrm{B} \& \mathrm{~B}$, respectively. For the later successional moss crust, $D_{c}$ decreased by $89.8 \%$ compared to the bare loess soil, where $68.9 \%$ and $20.9 \%$ contributed to the surface covering and B\&B, respectively. These results are helpful in understanding the influencing mechanism of BSCs on soil erosion and in developing the process-based erosion models for grassland and forestland. Copyright (C) 2017 John Wiley \& Sons, Ltd.

KEYWORDS: biological soil crusts; binding and bonding effects; contribution rate; rill erodibility; loess plateau

\section{Introduction}

Soil detachment, defined as the dislodgement of soil particles from the soil matrix at a particular location on the soil surface by the erosive force of rainfall and/or overland flow, provides loose, non-cohesive sediment for the subsequent transport and deposition (Zhang et al., 2003, 2009; Wang et al., 2013). Soil detachment by overland flow, such as rill erosion, is a crucial process of sediment generation on hillslopes (Poesen et al., 2003). It occurs when the scouring force of flowing water exceeds the threshold of soil resistance (Knapen et al., 2007). Therefore, the erosive force of overland flow and the resistance of near soil surface characteristics are two factors influencing the soil detachment process (Wang et al., 2014).

Overland flow is the external driving force for soil detachment (Zhang et al., 2003; Wang et al., 2014, 2015). For a given soil, hydraulics of overland flow (e.g. flow regime, discharge, depth, slope gradient, velocity, friction coefficient and sediment concentration) controls the process of detachment (Govers et al., 1990; Zhang et al., 2003). Soil detachment by overland flow is also strongly influenced by the near soil surface characteristics (i.e. soil properties, surface roughness, plant litter, biological soil crust and plant root system) since it occurs at the interface of flowing water and soil (De Baets et al., 2006, 2007; Knapen et al., 2007; Rodríguez-Caballero et al., 2012; Wang et al., 2014), especially on grassland and forestland.

As an important component of near soil surface characteristics in arid and semi-arid regions, biological soil crusts (BSCs) are an assemblage of specialized organisms including cyanobacteria, algae, lichens and moss (Williams et al., 1995; Belnap et al., 2001). In general, BSCs develop from the earlysuccessional cyanobacteria crust to the late-successional lichen and moss crusts (Ochoa-Hueso et al., 2011). Although BSCs represent a small fraction of the soil profile, they profoundly influence many soil surface characteristics known to affect hydrological processes (Belnap, 2006; Chamizo et al., 2012b; Rodríguez-Caballero et al., 2015; Liu et al., 2016). Previous studies reported that the presence of BSCs contributes cover and roughness to the soil surface, which absorb the energy of falling raindrops, modify soil surface interactions, and 
reduce shear effect and the velocity of overland flow, thereby minimizing the detachment of soil particles (Belnap, 2006; Rodríguez-Caballero et al., 2012). However, the effect of BSCs on the surface microtopography depends on the dominant types or successional stage of BSCs (Rodríguez-Caballero et al., 2015). It is widely accepted that the later successional BSCs composed of lichens and mosses growing above the soil surface add greater roughness than the early successional cyanobacteria crust (Belnap, 2006; Rodríguez-Caballero et al., 2015). Moreover, many studies have indicated that BSCs have the ability to enhance soil aggregates, resulting from the combination of physical binding effect (cyanobacteria filaments and moss rhizoids) and extruded bonding effect (polysaccharides and organic gels extruded by the cyanobacteria components) (Belnap, 2006; Chamizo et al., 2012a), thus decreasing the overland flow and soil detachment rate (Liu et al., 2016). Nevertheless, some other studies reported that BSCs reduced infiltration due to extrusion of hydrophobic compounds, which swell upon wetting, clogging soil pores, and enhancing runoff rate and soil detachment capacity by flowing water (Belnap, 2006; Wang et al., 2014).

The changes in soil surface characteristics induced by BSC growth certainly affect the soil detachment process of overland flow (Belnap, 2006; Chamizo et al., 2015). Knapen et al. (2007) investigated the effects of BSCs on soil detachment rate of concentrated flow in croplands and their results showed that BSCs significantly influenced soil detachment rate. The ability of the later succession moss crust was two times greater than the early succession algae curst in reducing soil detachment capacity. Wang et al. (2014) investigated the effects of near soil surface characteristics on soil detachment by overland flow on restored grassland. They found that BSCs contributed $14.9 \%$ to reduced soil detachment capacity of overland flow compared to the bare loess soil. Liu et al. (2016) quantified the effects of moss crust and mixed crust on the soil detachment process by overland flow on abandoned farmlands of the Loess Plateau and demonstrated that soil detachment capacity decreases exponentially with increase in BSC cover.

Generally, the roles of BSCs in promoting soil resistance to flowing water erosion can be attributed to the surface covering, and binding and bonding (B\&B) effects (Belnap, 2006; Knapen et al., 2007). The vertical structure of BSCs is characterized by a thin above-ground top crust and a sub-crust section with different physical and biological properties (Zhang et al., 2006; Sylvie and Peter, 2012). The above-ground top crust (reflecting the surface covering effect) can increase soil surface roughness (Belnap, 2006; Rodríguez-Caballero et al., 2012), thereby decreasing the velocity of flowing water and erosive force. Consequently, soil detachment capacity of overland flow declines (Wang et al., 2014). The sub-crust (reflecting the B\&B effects) constitutes cyanobacteria filaments and the anchoring structures of mosses and lichens. Analogous to plant root systems, they bind and connect soil particles together to enhance soil resistance to flow water erosion (Belnap et al., 2001; Belnap, 2006; Chamizo et al., 2009). Meanwhile, the cyanobacteria filaments can exude the extracellular polysaccharide materials to bond soil particles together though intermolecular bonding forces to increase soil aggregate stability (Knapen et al., 2007; Mager and Thomas, 2011). As a result, the soil detachment capacity of overland flow also decreases.

The Loess Plateau is one of the most severely eroded regions in the world, due to heavy storms, sparse vegetation cover and intense human activities (Fu et al., 2011). To control soil erosion, a long-term, policy-driven 'Grain for Green' project was implemented in 1999. More than 2 million hectares of lowyield steep farmlands $\left(>15^{\circ}\right)$ have been converted to forest lands or grasslands in the Loess Plateau to reduce soil erosion and improve soil quality (Deng et al., 2012). These changes in land uses lead to great variations in the near soil surface characteristics (Wang et al., 2014), which provide suitable water and heat conditions for BSC development and growth. Several field investigations revealed that cyanobacteria crust and moss crust are widely distributed in the Loess Plateau. In mature vascular plant communities, BSCs (dominated by moss crust) often cover up to $60-70 \%$ of the soil surface, whereas BSC (dominated by cyanobacteria crust) cover can be up to 90\% in the newly restored areas (Zhao et al., 2010, 2014).

BSCs have great effects on the soil detachment process by overland flow through surface covering and B\&B mechanisms, which likely vary with successional stages of BSCs. Some studies have been conducted to investigate and quantify the effects of BSCs on the soil detachment process of overland flow as a whole (Knapen et al., 2007; Wang et al., 2014). However, the relative contributions of BSC surface cover and B\&B effects to the process of soil detachment by overland flow are still not clear. Therefore, the objectives of this study were: (1) to detect the effects of surface covering and B\&B of BSCs on soil detachment by overland flow in chronological series of BSCs succession; and (2) to provide the correction coefficients of BSC factors (surface covering and B\&B) of different BSC types for rill erodibility and critical shear stress.

\section{Materials and Methods}

\section{Sampling sites}

The experiment was conducted at the Ansai Station of Soil and Water Conservation of Chinese Academy of Sciences, which locates a typical loess hill and gully region of the Loess Plateau. The region's climate is semiarid continental, with an average temperature of $8.8^{\circ} \mathrm{C}$ and an annual precipitation of $505 \mathrm{~mm}$, mostly in summer. Owing to poor management, most of the natural vegetation has been destroyed. Current principal land uses are grassland, woodland and wasteland. In this study, two abandoned hill slopes, located at Zhifanggou small watershed near the Ansai station, dominated by cyanobacteria crust (representing an early successional stage of BSC) and moss crust (representing a later successional stage of BSC) were selected for soil sampling (Table I). The roughness, intensity and type of pre-disturbance and vascular plant cover are fairly homogeneous for these sites. The physical properties and major pant species of different abandoned hill slopes are listed in Table II.

\section{Treatments}

Three treatments (expressed as T0, T1 and T2) were designed in this study to evaluate the potential effects of BSC cover and B\&B of two typical BSCs on soil detachment by overland flow. The bare loess soil (The $3 \mathrm{~cm}$ layer of cyanobacteria crust and moss crust were removed, keeping just the undisturbed loess soil without BSC tissue) of TO. This used as the baseline because: (1) this can eliminate the influence of sub-crust tissue (confined to $0-2 \mathrm{~cm}$ ) on soil detachment capacity; (2) BSCs significantly influence subsurface soil properties - in order to accurately quantify the effects of surface covering, B\&B of BSCs on soil detachment capacity by overland flow, bare loess soil must avoid sharing similar properties to BSCs. For T1, the top crust was removed slightly using tweezers and a soft brush, and believed to have only B\&B effects on soil mass. To ensure maximum elimination of interference to the sub-crust (cyanobacteria filaments and the anchoring structures of 
Table I. Basic information of the sampling sites; all sites have a similar hillside landform and all soil types are loess

\begin{tabular}{lccccc}
\hline & & & & Vegetation characteristics & \\
\cline { 3 - 6 } Dominant crust type & BSCs coverage (\%) & Location & Elevation (m) & Coverage (\%) & Primary vegetation \\
\hline Cyanobacteria crust & 82 & $36^{\circ} 44^{\prime} 35.7^{\prime \prime} \mathrm{N}, 109^{\circ} 18^{\prime} 54.8^{\prime \prime} \mathrm{E}$ & 1247 & 35 & $\begin{array}{c}\text { Artemisia capillaris Thunb. } \\
\text { Moss crust }\end{array}$ \\
\hline
\end{tabular}

Table II. Soil properties of sampling sites

\begin{tabular}{|c|c|c|c|c|c|c|}
\hline \multirow[b]{2}{*}{ Crust types } & \multirow{2}{*}{$\begin{array}{l}\text { Cohesion } \\
\qquad(\mathrm{kPa})\end{array}$} & \multicolumn{3}{|c|}{ Particle size distribution } & \multirow{2}{*}{$\begin{array}{c}\text { Organic matter } \\
\qquad\left(\mathrm{g} \mathrm{kg}^{-1}\right)\end{array}$} & \multirow{2}{*}{$\begin{array}{c}\text { Water-stable } \\
\text { aggregates } \\
(0-1)\end{array}$} \\
\hline & & Clay (\%) & Silt (\%) & Sand (\%) & & \\
\hline Cyanobacteria crust & $10.56 \pm 2.45^{\mathrm{a}}$ & 15.05 & 63.37 & 21.59 & $7.38 \pm 0.34^{\mathrm{a}}$ & $0.45 \pm 0.01^{\mathrm{a}}$ \\
\hline Bare1 & $8.71 \pm 0.23^{b}$ & 13.23 & 62.18 & 24.29 & $6.14 \pm 0.19^{b}$ & $0.40 \pm 0.03^{\mathrm{ab}}$ \\
\hline Moss crust & $12.75 \pm 2.18^{\mathrm{C}}$ & 16.52 & 62.61 & 20.88 & $7.41 \pm 0.26^{a}$ & $0.67 \pm 0.03^{\mathrm{c}}$ \\
\hline Bare2 & $9.23 \pm 1.41^{b}$ & 11.83 & 62.23 & 25.94 & $6.62 \pm 0.32^{b}$ & $0.53 \pm 0.03^{\mathrm{bd}}$ \\
\hline
\end{tabular}

Note: Values given represent average values \pm standard deviation. The same letter means that differences are not significant at $p<0.05$.

mosses), BSCs underwent atmospheric exposure before operations (crustal components above ground are brittle and easily removed, especially when they are dry). Compared with the baseline T0, T1 only had sub-crust effects, reflecting the B\&B effects of BSCs on the process of soil detachment by overland flow. For T2, both top crust and sub-crust were included, representing the total effect of BSCs. The characteristics of BSCs under different treatments are listed in Table III.

\section{Soil sampling and soil detachment capacity measurement}

Intact soil samples were collected using steel rings (diameter $10 \mathrm{~cm}$, height $5 \mathrm{~cm}$ ) from the topsoil surface to measure soil detachment capacity by overland flow. Detailed sampling procedures can be found in previous studies (Zhang et al., 2003). To quantify the effect of BSC surface cover and B\&B on the soil detachment process of overland flow, each treatment was tested for five replicates under each flow shear stress (a total of six shear stresses). In total, for two BSC types and bare loess soil, 150 tests $(2$ crust types $\times 2$ treatments $\times 6$ shear stresses $\times 5$ replications + bare loess soil $\times 6$ shear stresses $\times 5$ replications) were conducted. To ensure the same soil moisture, the collected soil samples were saturated for $8 \mathrm{~h}$ and then drained for $12 \mathrm{~h}$ for soil detachment capacity measurement.

Soil detachment capacity was measured in a $4.0 \mathrm{~m}$ long and $0.35 \mathrm{~m}$ wide flume (Figure 1). The test loess soil was glued on the flume bed surface to simulate the soil sample surface condition (Zhang et al., 2003). Flow discharge was controlled by a series of valves and measured at the flume outlet with a plastic bucket and a volumetric cylinder. For a given combination of flow discharge and slope gradient, the maximum velocity at the water surface was measured using a fluorescent dye method 12 times and modified by a reduction factor according to flow regime to obtain the average velocity (Luk and Merz, 1992). The average velocity was used to calculate the flow depth $h(\mathrm{~m})$ :

$$
h=\frac{Q}{B V}
$$

where $Q$ is the flow discharge $\left(\mathrm{m}^{3} \mathrm{~s}^{-1}\right), B$ is the flume width $(\mathrm{m})$ and $v$ is the mean flow velocity $\left(\mathrm{m} \mathrm{s}^{-1}\right)$. The calculated average flow depth varied from 0.0030 to $0.0056 \mathrm{~m}$ in this study. The flow shear stress $(\tau, \mathrm{Pa})$ was calculated as follows:

$$
\tau=\rho_{w} g h S
$$

where $\rho_{w}$ is the density of water $\left(\mathrm{kg} \mathrm{m}^{-3}\right), \mathrm{g}$ is the constant of gravity $\left(\mathrm{m} \mathrm{s}^{-2}\right)$ and $S$ is the slope gradient $\left(\mathrm{m} \mathrm{m}^{-1}\right)$. Six combinations of flow discharge $\left(0.0043-0.01 \mathrm{~m}^{2} \mathrm{~s}^{-1}\right)$ and flume bed gradient $(17.4-42.3 \%)$ were utilized in this study, resulting in six different shear stresses of 6.65, 9.45, 12.46, 15.12, 17.98 and $21.21 \mathrm{~Pa}$, respectively (Table IV).

The flume bed gradient and flow discharge were adjusted to the desired values. The soil sample was set into a hole on the flume bed $(0.5 \mathrm{~m}$ from the flume outlet) and was scoured under the desired flow shear stress and ended until a certain scouring depth was reached to standardize the influence of the ring rim (Nearing et al., 1991; Zhang et al., 2003). The scouring time varied from 15 to $600 \mathrm{~s}$. Soil detachment capacity was calculated as follows:

$$
D_{c}=\frac{W_{b}-W_{e}}{t \times A}
$$

where $W_{b}$ is the dry weight of soil sample before detachment test $(\mathrm{kg}), W_{e}$ is the dry weight of soil sample after detachment

Table III. The BSCs treatment participated in the process of soil detachment by overland flow

\begin{tabular}{lll}
\hline Treatment name & Surface of subsurface factors & \\
\hline T0 & Undisturbed loess soil & Baseline condition \\
T1 & Undisturbed sub-crust & Effects of BSC's below-ground tissue, including chemical bonding and physical binding \\
T2 & Undisturbed biological soil crust & Total BSCs effects \\
\hline
\end{tabular}



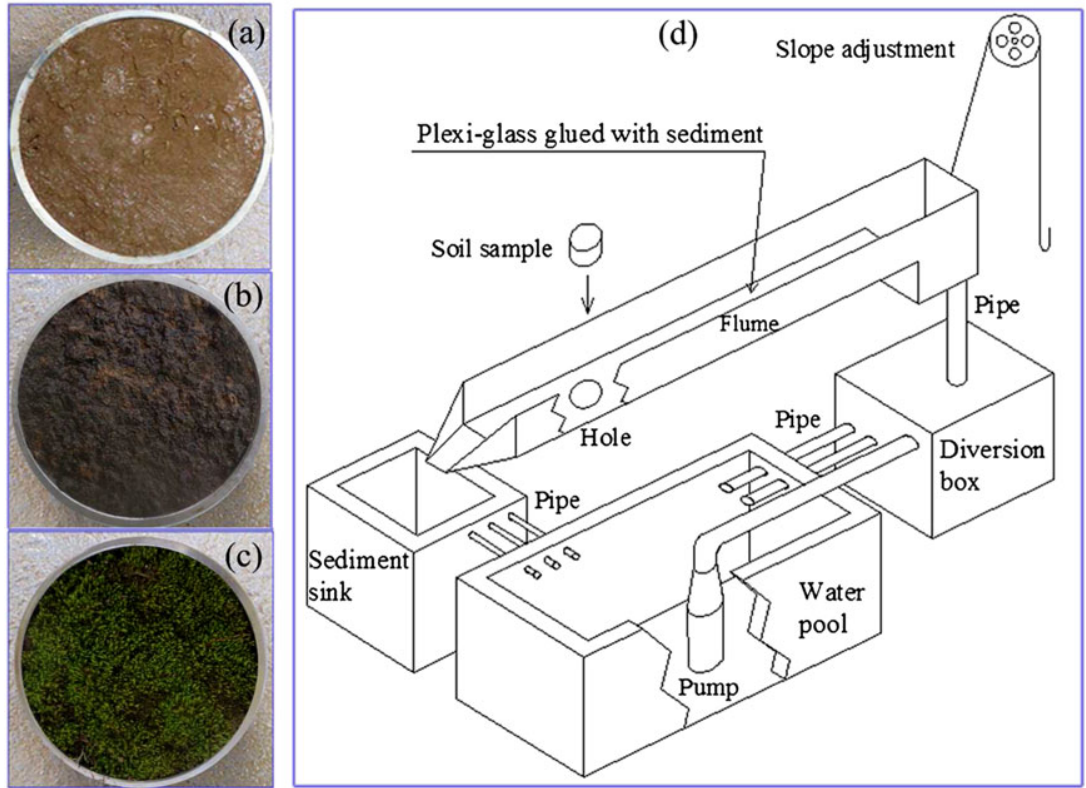

Figure 1. Soil sampling and experimental setup: (a) bare soil; (b) cyanobacteria crust; (c) moss crust; (d) schematic diagram of the flume experimental setup. [Colour figure can be viewed at wileyonlinelibrary.com]

Table IV. Hydraulic parameters used in this study

\begin{tabular}{lcccr}
\hline Flow discharge $\left(\mathrm{m}^{2} \mathrm{~s}^{-1}\right)$ & Slop gradient $(\%)$ & Mean flow velocity $\left(\mathrm{m} \mathrm{s}^{-1}\right)$ & Water depth $(\mathrm{mm})$ & Shear stress $(\mathrm{Pa})$ \\
\hline 0.0043 & 17.4 & 1.11 & 3.9 & 6.65 \\
0.0071 & 17.4 & 1.30 & 5.6 & 9.45 \\
0.0043 & 42.3 & 1.44 & 3.0 & 12.46 \\
0.0057 & 42.3 & 1.58 & 5.4 & 15.12 \\
0.0100 & 34.2 & 1.88 & 5.1 & 17.98 \\
0.0100 & 42.3 & 1.96 & 21.21 \\
\hline
\end{tabular}

test $(\mathrm{kg}), t$ is the test period (s) and $A$ is the section area of the soil sample $\left(\mathrm{m}^{2}\right)$. For each treatment, five samples were tested under each shear stress and the mean was deemed as the detachment capacity for that shear stress, crust treatment and crust type. The mean soil detachment capacity of six different shear stresses was used to analysis the contribution rates for each crust treatment and crust type.

\section{Reduction of detachment capacity and contribution rate}

The reductions of soil detachment capacity (RDC) caused by BSCs including sub-crust (B\&B effects) and top crust (cover effect) were calculated using Equations (4) and (5), and the total BSCs was calculated using Equation (6). The contribution rate (CR) to soil detachment was computed using Equation (7):

$$
\begin{aligned}
& \mathrm{RDC}_{\mathrm{BSC}-\mathrm{B} \& B}=D_{C-T 0}-D_{C-T 1} \\
& \mathrm{RDC}_{\mathrm{BSC}-\text { cover }}=D_{C-T 1}-D_{C-T 2} \\
& \mathrm{RDC}_{\text {Total-BSCS }}=D_{C-T 0}-D_{C-T 2}
\end{aligned}
$$

where RDC $_{\mathrm{BSC}-\mathrm{B} \& \mathrm{~B}}$ is the reduction of soil detachment capacity by the sub-crust $\left(\mathrm{kg} \mathrm{m}^{-2} \mathrm{~s}^{-1}\right), \mathrm{RDC}_{\mathrm{BSC} \text {-cover }}$ is the reduction of soil detachment capacity by top crust $\left(\mathrm{kg} \mathrm{m}^{-2} \mathrm{~s}^{-1}\right)$ and
$\mathrm{RDC}_{\text {Total-BSCs }}$ is the reduction of soil detachment capacity under undisturbed BSCs $\left(\mathrm{kg} \mathrm{m}^{-2} \mathrm{~s}^{-1}\right)$. $\mathrm{D}_{\mathrm{C}-\mathrm{TO}}, \mathrm{D}_{\mathrm{C}-\mathrm{T} 1}$ and $\mathrm{D}_{\mathrm{C}-\mathrm{T} 2}$ are the soil detachment capacity of T0, T1 and T2 $\left(\mathrm{kg} \mathrm{m}^{-2} \mathrm{~s}^{-1}\right)$, respectively:

$$
\mathrm{CR}_{i}=\frac{E_{i}}{\sum E_{i}} \times E_{\mathrm{Total}-\mathrm{BSCS}}
$$

where $\mathrm{CR}_{i}$ is the contribution rate of each factor $i$ (BSC surface covering, BSCs-B\&B, respectively) in reducing soil detachment capacity (\%). $E_{\text {Total-BSCs }}$ is the effect of intact BSCs on reducing soil detachment (\%, Equation (8)) and $E_{i}$ is the effect of factor $i$ on reducing soil detachment (\%; Equations (9) and (10)):

$$
E_{\text {Total-BSCs }}=\frac{\text { RDC }_{\text {Total-BSCs }}}{D_{C-T 0}} \times 100 \%
$$

$$
E_{\mathrm{BSCS}-\mathrm{B} \& B}=\frac{\mathrm{RDC}_{\mathrm{BSCS}-\mathrm{B} \& B}}{D_{C-T 0}} \times 100 \%
$$

$$
E_{\mathrm{BSCs}-\mathrm{cover}}=\frac{R D C_{B S C S-\text { cover }}}{D_{C-T 1}} \times 100 \%
$$

Note that $\mathrm{CR}_{\mathrm{BSCs}}-\mathrm{B} \& \mathrm{~B}+\mathrm{CR}_{\mathrm{BSCs}-\text { cover }}=\mathrm{CR}_{\text {Total }}-\mathrm{BSCs}$. 


\section{Rill erodibility and critical shear stress}

Rill erodibility $\left(K_{r}, \mathrm{~s} \mathrm{~m}^{-1}\right)$ and critical shear stress $\left(\tau_{c}, \mathrm{~Pa}\right)$ were estimated for each treatment as the slope and intercept on the $x$-axis of the regression linear line between flow shear stress $(\tau)$ and soil detachment capacity $\left(D_{c}\right)$ as described in the WEPP (Water Erosion Prediction Project) model (Nearing et al., 1989), as follows:

$$
D_{c}=K_{r}\left(\tau-\tau_{c}\right)
$$

where $K_{r}$ is the rill erodibility $\left(\mathrm{s} \mathrm{m}^{-1}\right), \tau$ is the flow shear stress $(\mathrm{Pa})$ and $\tau_{C}$ is the critical shear stress $(\mathrm{Pa})$.

\section{Statistical analysis}

The differences in $D_{c}$ between BSCs were detected by a method of multiple comparisons, which was also used for both RDC and CR. The relationship between $D_{C}$ and shear stress was fitted by a linear regression method, and the goodness of fit results were evaluated by the coefficient of determination. All statistical analyses and graphical displays were made using R 3.3.0 software for Windows ( $R$ Development Core Team, 2016).

\section{Results}

\section{Contributions of surface covering and B\&B on soil} detachment

The treatment of biological soil crust significantly influenced soil detachment capacity by overland flow. As seen in Figure 2, the bare loess soil (T0) shows higher soil detachment capacity than other treatments. For the cyanobacteria crust, the mean soil detachment capacity of sub-crust (T1) and undisturbed crust (T2) are $40.4 \%$ and $69.2 \%$ less than those of

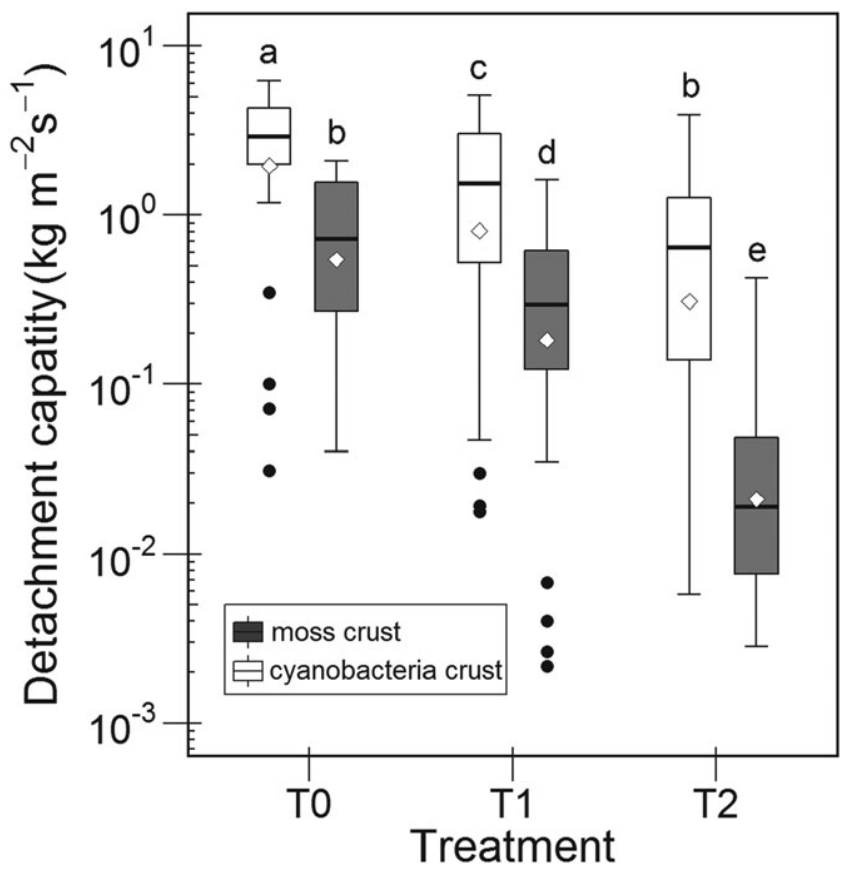

Figure 2. Variation of the soil detachment capacity for each treatment. T0 is the bare loess soil, T1 is the sub-crust (B\&B effects) and T2 is the total BSCs effect. The same letter means that differences are not significant at $p<0.05$. bare loess soil $\left(2.997 \mathrm{~kg} \mathrm{~m}^{-2} \mathrm{~s}^{-1}, \mathrm{~T} 0\right)$, respectively. The effects of the sub-crust (T1) and undisturbed crust (T2) of BSCs on soil detachment capacity of overland flow are obviously different between the cyanobacteria crust and moss crust (Figure 2). For the later successional moss curst, the mean soil detachment capacity of sub-crust (T1) and undisturbed crusts (T2) are $26.2 \%$ and $89.8 \%$ less than those of bare loess soil $\left(0.593 \mathrm{~kg} \mathrm{~m}^{-2} \mathrm{~s}^{-1}, \mathrm{~T} 0\right)$, respectively (Figure 2).

RDC caused by top crust, sub-crust and undisturbed crust are quite different (Table V). The mean RDC values under different treatments range from 0.865 to $2.075 \mathrm{~kg} \mathrm{~m}^{-2} \mathrm{~s}^{-1}$ for cyanobacteria crust, and varied from 0.155 to $0.534 \mathrm{~kg}$ $\mathrm{m}^{-2} \mathrm{~s}^{-1}$ for moss crust. These results indicated that BSCs could effectively enhance soil resistance to flowing water erosion though their surface covering and B\&B effects. As a surface phenomenon, BSCs shielded the soil surface and protected underlying soils from detachment by flowing water. Meanwhile, BSCs increased soil surface roughness and reduced flow velocity, thereby reducing the scouring of flowing water (effects of surface cover, which was represented by the treatment of top curst in this study). Below the soil surface, cyanobacteria filaments and moss rhizines bind soil particles together and form a matrix strongly influencing soil stability; cyanobacteria could increase soil aggregate stability by bonding soil particles with polysaccharide exudates $(B \& B$, represented by the treatment of sub-crust in this study).

As mentioned above, the top crust (surface covering) and the sub-crust $(B \& B)$ have key roles in reducing soil detachment capacity of overland flow. However, the contributions of the top crust and the sub-crust to the soil detachment process of overland flow remain unknown. Hence the contribution rates of top crust, sub-crust and undisturbed crust are calculated using Equation (7) and shown in Figure 3. For cyanobacteria crust, soil detachment capacity reduced by $69.2 \%$ compared to that of bare loess soil, where $37.7 \%$ and $31.5 \%$ are caused by top crust (surface covering) and sub-crust (B\&B). For moss crust, soil detachment capacity decreased by $89.8 \%$ compared to those of bare loess soil, where $68.9 \%$ and $20.9 \%$ are deduced by the top crust (surface covering) and sub-crust (B\&B). The contribution of the BSCs increased with BSC succession because later successional moss crust has more biomass above the soil surface. For example, the contribution of top crust (covering effect) of later successional moss crust was 1.8 times greater than that of the early successional cyanobacteria crust.

\section{Soil resistance to flowing water erosion with biological soil crusts succession}

Following Nearing et al. (1989), the soil resistance to flowing water erosion (rill erodibility $K_{r}$ and critical shear stress $\tau_{c}$ ) is estimated using the measured soil detachment capacity and flow shear stress. The fitted $K_{r}$ and $\tau_{c}$ of different treatments

Table V. Reduction in soil detachment capacity with different BSC characteristics relative to bare loess soil

\begin{tabular}{lcc}
\hline & \multicolumn{2}{c}{ Reduction of soil detachment capacity $\left(\mathrm{kg} \mathrm{m}^{-2} \mathrm{~s}^{-1}\right)$} \\
\cline { 2 - 3 } Factor & Cyanobacteria crust & Moss crust \\
\hline BSC $_{\text {cover }}$ & 0.865 & 0.377 \\
BSC $_{\text {B\&B }}$ & 1.210 & 2.559 \\
Total BSC & 2.075 & 2.36 \\
\hline
\end{tabular}




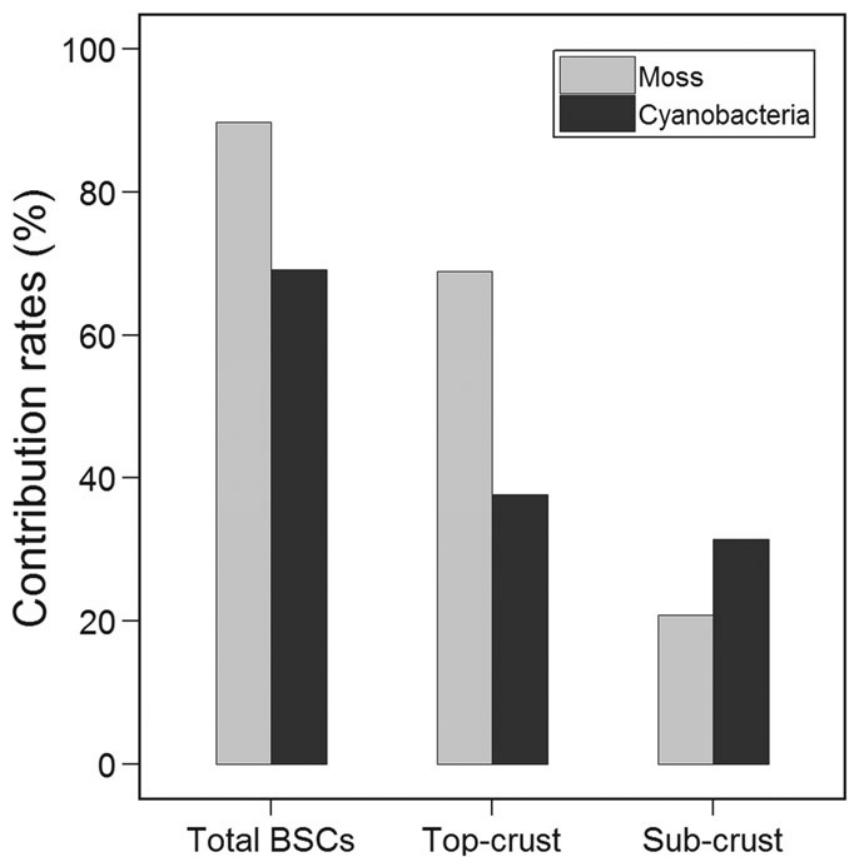

Figure 3. Contribution rates of different BSCs factors. Total BSCs are the undisturbed crusts; sub-crust is binding and bonding effect of BSCs; top-crust is the cover effect of BSCs.

for two BSCs are calculated using Equation (11) and are shown in Figure. 4. For the cyanobacteria crust, $K_{r}$ under T1 treatment (sub-crust) was reduced by $23.9 \%$ compared to that of bare loess soil $\left(\mathrm{T} 0,0.3404 \mathrm{~s} \mathrm{~m}^{-1}\right)$. When the cover effect of BSC is considered (T2, total cyanobacteria crust), $K_{r}$ is reduced by $41.6 \%$ compared to $\mathrm{T} 1$ treatment (sub-crust). For the moss crust, $K_{r}$ under T1 treatment (sub-crust) is reduced by $52.9 \%$ compared to the bare loess soil (T0, $0.1659 \mathrm{~s}$ $\mathrm{m}^{-1}$ ). Taking into consideration the surface covering effect, $K_{r}$ is reduced by $87.8 \%$ relative to that under $\mathrm{T} 1$ treatment (sub-crust). The critical shear stresses $\left(\tau_{c}\right)$ of cyanobacteria curst changed from 5.61 to $7.71 \mathrm{~Pa}$ and ranged from 6.47 to 8.04 Pa for moss crust (Figure 4). Compared to bare loess soil (T0), the critical shear stress of T1 treatment (sub-crust) and T2 treatment (total BSC) increased by $23.1 \%$ and $37.4 \%$ for cyanobacteria crust. Regarding the later successional moss crust, the critical shear stress of $\mathrm{T} 1$ treatment (sub-crust) and T2 treatment (total BSC) increased by $16.2 \%$ and $24.3 \%$ compared to that of the bare loess soil.

\section{Discussion}

Contributions of surface covering and B\&B on soil detachment

BSCs have a substantial impact on the process of soil detachment. Our results showed that the mean soil detachment capacity of bare loess soil is 3.2 times greater than that of cyanobacteria crust (T2), and the mean soil detachment capacity of base soil is 9.8 times higher than that of moss crust (T2). It is obvious that the later successional moss crust is more effective in reducing soil detachment capacity by overland flow than the early successional cyanobacteria crust. These results are consistent with the finding of Knapen et al. (2007), who investigated the effects of BSCs on soil detachment capacity of overland flow in croplands and showed that soil detachment capacity decreases with crust development. Eldridge and Greene (1994) also found, under simulated rainfall on a semiarid soil in Australia, that the splash erosion rate declined exponentially with increasing BSC coverage. In fact, it is widely accepted that the BSCs shield the soil surface from both wind and water erosion (Belnap, 2006; Knapen et al., 2007; Chamizo et al., 2015; Liu et al., 2016). However, some other studies reported that BSCs limited infiltration due to extrusion of hydrophobic compounds and clogging of soil pores when wetting, thus increasing the amount and velocity of water runoff, which determine the process governing overland flow generation (Belnap, 2006; Fischer et al., 2010; Chamizo et al., 2012a, 2012b; Rodríguez-Caballero et al., 2013). To examine the effects of BSCs on runoff and erosion, Zhao et al. (2013) found that, under different scouring water fluxes, the presence of BSCs plays a critical role in preventing soil erosion by water in semiarid regions, although there was potential increase in runoff. Liu et al. (2016) also reported that BSCs have a significant effect on soil detachment by overland flow, which could be estimated using flow shear stress and BSC coverage. Moreover, the erosion rate of BSC-covered surfaces is lower than the physical crust (Chamizo et al., 2009; Rodríguez-Caballero et al., 2013). Eldridge and Kinnell (1997) found that water erosion of BSC-covered soil is five times less compared to the physical crust (such as raindrop impact or depositional), mainly because both the external morphology and the internal structure of the physical crusts are quite different from BSCs (Belnap, 2006). In contrast, the presence of physical crust seals and smoothens surfaces, reduces infiltration and increases the velocity of overland flow (Chamizo et al., 2015). Using scanning
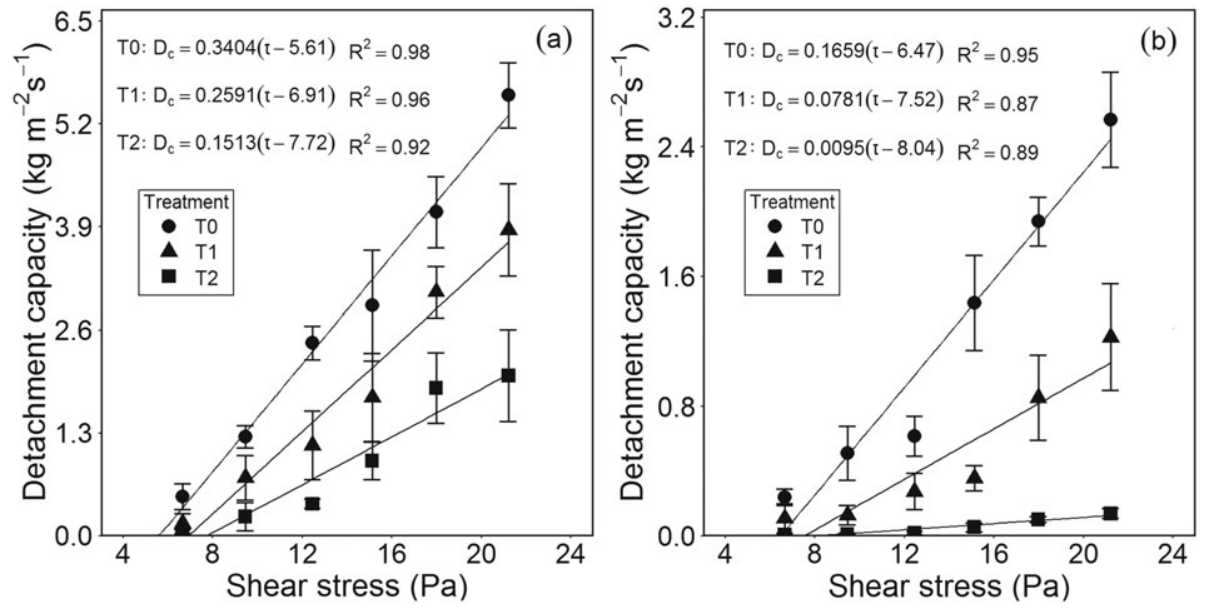

Figure 4. Soil detachment capacity $\left(D_{c}\right)$ as a function of shear stress $(\tau)$ as an example to estimate rill erodibility and critical shear stress: (a) cyanobacteria crust; (b) moss crust. 
electron microscopy, previous studies presented a detailed analysis of the internal structure of BSCs and physical crusts (Belnap, 2006; Zhang et al., 2006, Williams, 2012). In general, the role of BSCs in enhancing soil resistance to flowing water erosion is attributed to the surface cover (modifying the surface micro-topography, such as soil roughness), and B\&B effects (change soil structure). However, in previous studies, BSCs were regarded as a whole system in discussions of their effects on soil detachment process by overland flow (e.g. Knapen et al., 2007; Wang et al., 2013). Quantifying the effects of surface covering and B\&B of BSCs in reducing soil detachment capacity in this paper is helpful for understanding the soil erosion mechanism of soils covered by BSCs.

In this study, we found that the contributions of top crust (surface covering) increase with the stage of BSC development (cyanobacteria to moss) from $37.7 \%$ to $68.9 \%$ (Figure 3). For the cyanobacteria crust, the top crust is about 0-2 $\mathrm{mm}$ thick and is composed of small packed particles and most of the organic material (Hagai et al., 2015). Therefore, high-intensity precipitation and flow scouring can break apart the top crust of cyanobacteria, causing the detachment of subsoil. Unlike cyanobacteria crust, moss crust has most of its biomass above the soil surface, which is more effective in protecting the underlying soils from scouring by the overland flow (Belnap, 2006). Moreover, the top organisms of BSCs can absorb large amounts of water, increasing their volume several times over their dry volume (Belnap, 2006), which may affect the surface microtopography, and thus impact infiltration and soil erosion (Rodríguez-Caballero et al., 2015). However, water absorption capacity depends on the type of BSCs and the succesional stage. More development moss crust can expand their cover and biomass by up to 13 times when wetted, whereas the early successional cyanobacteria crust absorb up to eight times their dry weight (Belnap, 2006; Rodríguez-Caballero et al., 2015). Thus later successional moss crust confers greater roughness to soils than early successional cyanobacteria crust when wetted, and these structural differences in the top crust made the later successional moss crust more effective at stabilizing surfaces than the cyanobacteria crust.

Variation in the contribution of sub-crust was inversely related to the top crust; the contribution of sub-crust (B\&B effects) decreased with the stage of BSC development (cyanobacteria to moss) from $31.5 \%$ to $20.9 \%$ (Figure 3 ). As a pioneer crust, cyanobacteria are the first colonizers (Belnap, 2006; Chamizo et al., 2015); the sub-crust (B\&B effects) of cyanobacteria filaments can bind soil particles and contribute amounts of organic carbon via carbon fixation, which provides these soils with a tremendous resistance to movement of water (Belnap, 2006). We also found that the effect of cyanobacteria crust on organic matter and soil cohesion is, especially, significantly higher than bare loess soil (Table II), which greatly enhanced the effects of the top layer of soil in reducing soil detachment by overland flow. The contributions of sub-crust ( $B \& B$ effects) of cyanobacteria are significant and accounted for nearly half of the effects of the total cyanobacteria crust. The sub-crust (B\&B effects) of moss also plays an important role in protecting the soil from erosion through anchoring structures binding soil particles to increase soil aggregate stability and soil cohesion (Table II). However, for the later successional moss crust, the mean soil detachment capacity of bare loess soil was reduced by $80.2 \%$ compared to that of cyanobacteria crust, which can be attributed to the differences in soil properties, such as cohesion, organic matter content and water-stable aggregate, as shown in Table II. Therefore, the contribution of sub-crust of moss is lower than that of cyanobacteria crust in improving the resistance of the soil to flowing water.
As discussed above, BSCs significantly affect soil detachment capacity by overland flow through modifying the surface microtopography and enhancing soil aggregates, and the different developmental stages of BSCs have different effects on the hydrological and erosive response of soils covered by BSCs at patch scale (Rodríguez-Caballero et al., 2012). When the later successional-stage BSCs cover the spaces between vascular plants, it is likely that infiltration would increase and erosion would decrease. Moreover, at hillslope scale, BSCs would roughen the soil surfaces, causing slower overland flow, allowing more time for infiltration and decreasing the scouring force of flowing water. More generally, we expect BSCs to influence the hydrological and geomorphological processes at a much larger scale (e.g. landscape scale).

\section{Soil resistance to flowing water erosion with biological soil crusts succession}

Rill erodibility $\left(K_{r}\right)$ and critical shear stress $\left(\tau_{c}\right)$ are two important parameters reflecting the effects of soil resistance to erosive forces (Nearing et al., 1989). For the early successional cyanobacteria crust, rill erodibility $\left(K_{r}\right)$ of bare loess soil (T0) was 1.3 and 2.2 times greater than those of the T1 treatment (sub-crust) and T2 treatment (total curst), while, for the later successional moss crust, rill erodibility $\left(K_{r}\right)$ of base soil (T0) was 2.1 and 17.5 times greater than those of the T1 treatment (sub-crust) and T2 treatment (total curst). These results imply that the effects of both top crust (covering effect) and sub-crust (B\&B) of BSCs can increase the resistance of the soil to scouring by the overland flow. Other authors (e.g. Belnap, 2006; Liu et al., 2016) pointed out that the BSCs not only create a coherent living crust that covers the soil surface, but also that, underneath the top crust, filaments and residual organic matter also bind with the soil particles, strongly enhancing soil stability. In this study, we found that the top crust (surface covering) has a larger effect than the sub-crust (B\&B) on increasing the soil resistance to erosion by flowing water, especially for the later successional moss crust. This is likely due to the surface covering effect of BSCs, which reduces the contact area of flow water with the soil particles, thus weakening the shear force to separate soil particles. This agrees with Liu et al. (2016), who studied the influence of BSC coverage on soil detachment by overland flow, and who pointed out that rill erodibility of bare soil is significantly greater than those of BSCs; covered soil and rill erodibility decrease with coverage of BSCs. Furthermore, the later successional moss crust coverage is more effective in reducing soil erosion rate than the early successional crust (Knapen et al., 2007). Eldridge and Greene (1994) also reported an exponential decline in sediment removal by splash with increasing BSC cover in a semiarid context. Although a different erosion process was studied, it is plausible that the later successional moss crust is more effective in reducing soil erosion rates than the early successional crust.

Soil detachment in rills occurs when flow shear stress exceeds the critical shear stress of the soil (Wang et al., 2013). Our results demonstrated that the presence of such crusts on the soil surface increases the flow shear stress needed to overcome the impacts of BSCs on soil stability. As seen in Figure 4, the critical shear stress $\left(\tau_{c}\right)$ of sub-crust (T1) and total crust (T2) were 1.2 and 1.4 times higher than those of bare loess soil (T0, 5.61 Pa) for the cyanobacteria crust, while, for the later successional moss curst, critical shear stress $\left(\tau_{c}\right)$ of sub-crust (T1) and total curst (T2) were 1.1 and 1.2 times greater than those of bare soil (T0, 6.47 Pa). This is supported by the rill erodibility found, which showed that both top crust (covering 
effect) and sub-crust (B\&B) of BSCs play a critical role in soil stabilization. Knapen et al. (2007) studied the influence of BSCs on the soil detachment by overland flow in croplands, and pointed out that the later successional moss crust was more effective in increasing critical shear stress than the early successional algae crust and bare soil. Moreover, in their flume experiments on the Loess Plateau of China, Wang et al. (2013) found that the critical shear stress increased with increasing thickness of BSCs. However, no differences were found between different BSC cover classes for moss crust (Liu et al., 2016), which was probably caused by the choice of sampling. In a previous study (Liu et al., 2016), we found that BSCs with different coverages were selected for soil sampling, which means that the samples are a complex mosaic of BSCs and bare soil. This may result in samples' uneven loading when flow scouring, thus affecting the critical shear stress of soil-covered BSCs.

\section{Conclusions}

After calculating the contribution of different types of BSC factors (top crust and sub-crust) on soil detachment capacity by overland flow, we found that BSCs have great effects on the soil detachment process through surface covering and B\&B mechanisms. However, the effect of BSCs on soil detachment capacity depends on the type or developmental stage of the BSCs. For the early successional cyanobacteria crust, soil detachment capacity reduces by $69.2 \%$ compared to the bare loess soil, of which $37.7 \%$ and $31.5 \%$ are attributed to surface cover and B\&B; for the later successional moss crust, soil detachment capacity decreases by $89.8 \%$ compared to the bare loess soil, of which $68.9 \%$ and $20.9 \%$ are attributed to surface covering and B\&B. Moreover, we also found that both soil detachment capacity and rill erodibility decrease with BSC succession. Meanwhile, the presence of BSCs obviously increases the critical shear stress, especially for the later successional moss crust. Generally, the accumulated effects of top crust (covering effect) and sub-crust $(B \& B)$ of BSCs enhance the ability of the soil to resist detaching by overland flow, and the effect of top crust (covering effect) plays an increasingly important role in reducing soil detachment as the BSCs succession. The findings of this study are helpful in understanding the influencing mechanism of BSCs on soil erosion and in developing process-based erosion models for grassland and forestland.

Acknowledgements - This study was funded by the National key R\&D Program of China (2017YFC0504702), the State Key Program of National Natural Science Foundation of China (No.41530858) and the Fund for Creative Research Groups of the National Natural Science Foundation of China (No.41621061). The authors thank the members of the Ansai Research Station of Soil and Water Conservation, the Chinese Academy of Sciences and the Ministry of Water Resources for technical support.

\section{References}

Belnap J. 2006. The potential roles of biological soil crusts in dryland hydrologic cycles. Hydrological Processes 20: 3159-3178.

Belnap J, Rosentreter R, Leonard S, Kaltenecker JH, Williams J, Eldridge D. 2001. Biological soil crusts: ecology and management. US Department of the Interior, Bureau of Land Management, National Science and Technology Center, Information and Communications Group, Denver, CO.

Chamizo S, Cantón Y, Afana A, Domingo F, Benet AS, Lázaro R. 2009. How development and disturbance of biological soil crust do affect runoff and erosion in drylands? María Asunción Romero Díaz: 203-206.
Chamizo S, Cantón Y, Miralles I, Domingo F. 2012a. Biological soil crust development affects physicochemical characteristics of soil surface in semiarid ecosystems. Soil Biology and Biochemistry 49: 96-105.

Chamizo S, Cantón Y, Rodríguez-Caballero E, Domingo F, Escudero A. 2012b. Runoff at contrasting scales in a semiarid ecosystem: a complex balance between biological soil crust features and rainfall characteristics. Journal of Hydrology s 452-453: 130-138.

Chamizo S, Rodríguez-Caballero E, Cantón Y, Asensio C, Domingo F. 2015. Penetration resistance of biological soil crusts and its dynamics after crust removal: relationships with runoff and soil detachment. Catena 126: 164-172.

De Baets S, Poesen J, Gyssels G, Knapen A. 2006. Effects of grass roots on the erodibility of topsoils during concentrated flow. Geomorphology 76: 54-67.

De Baets S, Poesen J, Knapen A, Galindo P. 2007. Impact of root architecture on the erosion: reducing potential of roots during concentrated flow. Earth Surface Processes and Landforms 32: 1323-1345.

Deng L, Z-p S, Li R. 2012. Effects of the grain-for-green program on soil erosion in China. International Journal of Sediment Research 27: 120-127.

Eldridge D, Greene R. 1994. Microbiotic soil crusts: a review of their roles in soil and ecological processes in the rangelands of Australia. Soil Research 32: 389-415.

Eldridge DJ, Kinnell PIA. 1997. Assessment of erosion rates from microphyte-dominated calcareous soils under rain-impacted flow. Australian Journal of Soil Research 35: 475-489.

Fischer T, Veste M, Wiehe W, Lange P. 2010. Water repellency and pore clogging at early successional stages of microbiotic crusts on inland dunes, Brandenburg, NE Germany. Catena 80: 47-52.

Fu B, Liu Y, Lü Y, He C, Zeng Y, Wu B. 2011. Assessing the soil erosion control service of ecosystems change in the Loess Plateau of China. Ecological Complexity 8: 284-293.

Govers G, Everaert W, Poesen J, Rauws G, De Ploey J, Lautridou JP. 1990. A long flume study of the dynamic factors affecting the resistance of a loamy soil to concentrated flow erosion. Earth Surface Processes and Landforms 15: 313-328.

Hagai R, Felde VJMNL, Stephan P, Sylvie D, Danny I, Gil E, Haim T, Peter FH, Berkowicz SM, Nir K. 2015. 3D structure and cyanobacteria activity within a desert biological soil crust. Environmental Microbiology 18: 372-383.

Knapen A, Poesen J, Galindo-Morales P, Baets SD, Pals A. 2007. Effects of microbiotic crusts under cropland in temperate environments on soil erodibility during concentrated flow. Earth Surface Processes and Landforms 32: 1884-1901.

Liu F, Zhang GH, Sun L, Wang H. 2016. Effects of biological soil crusts on soil detachment process by overland flow in the Loess Plateau of China. Earth Surface Processes and Landforms 41: 875-883.

Luk S, Merz W. 1992. Use of the salt tracing technique to determine the velocity of overland flow. Soil Technology 5: 289-301.

Mager DM, Thomas AD. 2011. Extracellular polysaccharides from cyanobacteria soil crusts: a review of their role in dryland soil processes. Journal of Arid Environments 75: 91-97.

Nearing M, Foster G, Lane L, Finkner S. 1989. A process-based soil erosion model for USDA-water erosion prediction project technology. Transactions of the ASAE 32: 1587-1593.

Nearing M, Bradford J, Parker S. 1991. Soil detachment by shallow flow at low slopes. Soil Science Society of America Journal 55: 339-344.

Ochoa-Hueso R, Hernandez RR, Pueyo JJ, Manrique E. 2011. Spatial distribution and physiology of biological soil crusts from semi-arid central Spain are related to soil chemistry and shrub cover. Soil Biology and Biochemistry 43: 1894-1901.

Poesen J, Nachtergaele J, Verstraeten G, Valentin C. 2003. Gully erosion and environmental change: importance and research needs. Catena 50: 91-133.

R Development Core Team. 2016. R: A Language and Environment for Statistical Computing. Version 3.3.0. The R Foundation for Statistical Computing: Vienna. http://www.R-Project.org

Rodríguez-Caballero E, Cantón Y, Chamizo S, Afana A, Solé-Benet A. 2012. Effects of biological soil crusts on surface roughness and implications for runoff and erosion. Geomorphology 145: 81-89. 
Rodríguez-Caballero E, Cantón Y, Chamizo S, Lázaro R, Escudero A. 2013. Soil loss and runoff in semiarid ecosystems: a complex interaction between biological soil crusts, micro-topography, and hydrological drivers. Ecosystems 16: 529-546.

Rodríguez-Caballero E, Aguilar MÁ, Castilla YC, Chamizo S, Aguilar FJ. 2015. Swelling of biocrusts upon wetting induces changes in surface micro-topography. Soil Biology and Biochemistry 82: 107-111.

Sylvie LD, Peter FH. 2012. An electronic micropenetrometer (EMP) for field measurements of biological soil crust stability. Journal of Plant Nutrition and Soil Science 175: 519-520.

Wang B, Zhang GH, Shi YY, Zhang XC, Ren ZP, Zhu LJ. 2013. Effect of natural restoration time of abandoned farmland on soil detachment by overland flow in the Loess Plateau of China. Earth Surface Processes and Landforms 38: 1725-1734.

Wang B, Zhang GH, Zhang X, Li ZW, Su ZL, Yi T, Shi Y-Y. 2014. Effects of near soil surface characteristics on soil detachment by overland flow in a natural succession grassland. Soil Science Society of America Journal 78: 589-597.

Wang B, Zhang GH, Shi YY, Li ZW, Shan ZJ. 2015. Effects of near soil surface characteristics on the soil detachment process in a chronological series of vegetation restoration. Soil Science Society of America Journal 79: 1213-1222.

Williams AJ. 2012. Biological soil crusts in the Mojave Desert, USA: micromorphology and pedogenesis. Soil Science Society of America Journal 76: 1685-1695.
Williams J, Dobrowolski J, West N. 1995. Microphytic crust influence on interrill erosion and infiltration capacity. Transactions of the ASAE 38: 139-146.

Zhang GH, Liu BY, Liu GB, He XW, Nearing M. 2003. Detachment of undisturbed soil by shallow flow. Soil Science Society of America Journal 67: 713-719.

Zhang GH, Mk T, Zhang X. 2009. Temporal variation in soil detachment under different land uses in the Loess Plateau of China. Earth Surface Processes and Landforms 34: 1302-1309.

Zhang YM, Wang HL, Wang XQ, Yang WK, Zhang DY. 2006. The microstructure of microbiotic crust and its influence on wind erosion for a sandy soil surface in the Gurbantunggut Desert of Northwestern China. Geoderma 132: 441-449.

Zhao Y, Xu M. 2013. Runoff and soil loss from revegetated grasslands in the hilly Loess Plateau region, China: influence of biocrust patches and plant canopies. Journal of Hydrologic Engineering 18: 387-393.

Zhao Y, Xu M, Belnap J. 2010. Potential nitrogen fixation activity of different aged biological soil crusts from rehabilitated grasslands of the hilly Loess Plateau, China. Journal of Arid Environments 74: 1186-1191.

Zhao Y, Qin N, Weber B, Xu M. 2014. Response of biological soil crusts to raindrop erosivity and underlying influences in the hilly Loess Plateau region, China. Biodiversity and Conservation 23: 1669-1686. 